a middle maximum, as a reference to my former letter ( $N^{\top} A T U R E$, vol. viii. p. 245) will show; and I do not find any reference to 1846 as a maximum in Prof. Tyndall's letter, or in that of Mr. Symons, which alone I had seen when I last wrote. In both of these 1848 is named, and I demur to the changes to 1849 and 1872 ; to the first because, apparently without any sufficient reason, a dry year (48.10 inches) is discarded, and a wet year $(67.88$ inches $)$ is added, and to the second, not because it affects my calculations, but because no reason is given. The change appears to favour Mr. Meldrum's views, but it scarcely does so, because the estimated quantity of 65 inches in 1873 resulted in an actual average of only $5 \mathrm{I}^{\circ} 26$ inches, which would make a difference of $13^{\circ} 74$ inches in that year, and would change the trifling excess of 2.64 inches on the maximum side into a larger excess of II'IO inches on the minimum side.

It is unnecessary, however, to go beyond the calculation which I have above submitted to show that Barbados does not bear out Mr. Meldrum's theory. I am quite prepared to agree with him that, if the preponderance of evidence drawn from a wider area and from longer periods does support it, the opposite results obtained in Barbados, although it is most favourably situated for observations of this nature, being fully exposed to the trade winds blowing over the Atlantic during the greater part of the year, and not apparently subject to any disturbing influences, only show that no particular locality can draw a safe inference as to the manner in which the presence or absence of sun-spots is likely to affect it.

A further consequence presents itself to my mind. It appears to me that the atmospheric influences entering into this question -chiefly evaporation and rainfall--must balance one another pretty equally over the face of the globe, either contemporaneously or by seasons; that the excess of rain received by some places has been drawn from others, which have consequently experienced the opposite effects of evaporation and drought. If therefore certain solar influences, whose presence is indicated by the appearance of sun-spots, have the effect of causing m excess of rain in certain years over so wide an area as $\mathrm{Mr}$. Meldrum supposes, whence does this excess come? If from some atmor spheric reservoir, independent of the globe, the excess would be general; the alternations of rain and drought might vary by years or by seasons, more or less long, but not cintemporaneously by, or in, localities. If, however, they be drawn from the earth, or from atmospheric strata near the earth, there must be evaporation and drought in those parts whence the excess is drawn. Barbados, as I have pointed out, is singularly free from local influences which would affect its rainfall differently from the rest of the globe. When therefore $I$ find the experience of Barbados differing from that of Mauritius, and of many other parts of the world, 1 am driven to the conclusion that the influences indicated by the existence of sun-spots are not universal, although they may possibly operate on, and intensify, other influences alreary existing from other causes; and that the absence of those infinences and the existence of difierent effects in Barbados is not an exceptional result, but a necessary consequence, to be expected in other parts of the globe also, and to be anticipated from the ordinary operation of known physical laws. I shall not, however, be dogmatic on the point, and shall hail further proof of the correctness of Mr. Meldrum's theory as a welcome contribution to the "Meteorology of the future."

RAWSON W. RAWSON

\section{Care of Rabbits for their Dead}

SEVERal months ago you published, among others, a letter of mine, on the "care of monkeys for their dead." Since then $X$ have been making observations upon a similar attention displayed by rabbits, although the considerations which lead 10 its exercise are apparently much more practical than in the case of monkeys.

Most people are aware that if a rabbit is shot near the mouth of its burrow, the animal will employ the last remnant of its life in struggling into it. Having several times observed that wounded rabbits which had thus escaped appeared again several days afterwards above-ground, lying dead a few feet from the mouth of the burrow, I wished to ascertain whether the wounded animals had themselves come out before dying-possibly for air, - - or had been taken out after death by their companions. therefore shot numerous rabbits while they were sitting near their burrows, taking care that the distance between the gun and the animal should be such as to ensure a speedy, though not an immediate, death. Having marked the burrows at which $I$ shot rabbits in this manner, I returned to them at intervals for a fortnight or more, and found that about one half of the bodies appeared again on the surface in the way described. That this reappearance above-ground is not due to the victim's own exertions, I am now quite satisfied; for not only did two or three days generally elapse before the body thus showed itself-a period much too long for a severely wounded rabbit to survive, - - but in a number of cases decomposition had set in. Indeed, on one occasion scarcely anything of the animal was left, save the skin and bones. This was in a large warren.

It is a curious thing that $I$ have hitherto been unable to get any bodies returned to the surface, of rabbits which I inserted into their burrows after death. I account for this by supposing that the stench of the decomposing carcase is not so intolerable to the other occupants of the burrow, when it is near the orifice, as it is when further in. Similarly, I find that there is not so good a chance of bodies being retumed from an extensive warren of intercommunicating holes, as there is from smaller warrens or blind holes; the reason probably being, that in the one case the living inhabitants are free to vacate the offensive locality, while in the other case they are not so. Anyhow, there can be no reasonable doubt that the instinct of removing their dead has arisen in rabbits, from the necessity of keeping their confined domiciles in a pure condition.

Dunskaith, Ross-shire, July 26 GEORGE J. ROMANES

\section{THE NEWFOUNDLAND SEAL FISHERY*}

THE vessels employed in this fishery are generally built for the purpose at Aberdeen, Greenock, or Dundee; but some obsolete men-of-war have been bought and strengthened to meet the requirements of the trade. Those steamers built for the purpose range from $x 70$ to 4.70 tons register, and have screw propellers. The Bear, in which I went, belonging to Messrs. Walter Green and Co., and commanded by Captain Alexander Graham, a sealing master of thirty years' experience, was a new vessel of the largest class, built by Messrs. Stephens, of Dundee, was barquentine rigged, and had compound engines of IIO H.P.

The smallest rod in the latter was $2 \frac{1}{3}$ inches in diameter, the minimum that has been found to stand the shock of concussion with the ice. Propellers are made in one piece of cast-iron; metal having been tried was found to twist, and those made with separate blades to screw in inevitably broke in the thread of the screw. They are about 7 in. in thickness near the boss and about 2 in. at the point, and should be made without a sling hole, two propellers of the Bear having broken at that place. Over the banjo frame are the "slip boards," pieces of hard wood about 3 in. thick, that slide down the screw well on each side of the Sampson posts to prevent ice getting in above the propeller. They should be made to hoist up in one piece with the banjo, otherwise considerable time is lost in unbolting them. The brine from salt-meat casks is kept and poured down boiling to loosen the gear set fast by frost and ice. The propeller may be known to be broken by the great increase in vibration that inevitably follows when in the ice. After watching for a long time I found the effect produced on the engines by the ship striking the ice was scarcely perceptible, and the stoppage of the propeller by ice even at full speed only caused the connecting rod to vibrate slightly.

The bows for about $20 \mathrm{ft}$. from the stem are built nearly solid with the numerous beams, timbers, and diagonals; this space is called "the fortification." The bows are sharply built with a raking gripe, the advantage of which is that the vessel does not strike the ice on all the stem at once, but gradually meets the pan, and by the force of the way runs on it as up an inclired plane, and thus adds weight to momentum in breaking a passage. The stern should be

* The following notes from personal experience were made in the present year by Navigating Lieutenant Wm. Maxwell, R.N., and communicated to the Hydrographer of the Admiralty. 
full, to carry the ice clear of the propeller, a fine run having a tendency to guide the ice into the screw well.

The vessels are surrounded completely with iron-wood bark about three inches thick; the stern has an iron plate down it, the rudder is sheathed on both sides and abaft, and from the stem about ten feet aft iron plating about half an inch in thickness is bolted. The rudder hole is unusually large to admit a rapid change, and chains are used for steering with.

The "sheer poles" two long spars, are crossed and lashed at one end and suspended from the bows with heavy chains that cross from the bowsprit-cap and one of the other ends on each side from the cat-head. They are intended for men to jump on from the ice when coming on board, or as a temporary resting-place when breaking the ice from the bows or guiding the vessel, and for those purposes man-ropes are slung and a ladder led from the bulwarks to them and the ice. "Pokers," Iong poles with iron spikes, are used as levers to move the ice, and occasionally as tracking poles. The "crows" nest" is a barrel lashed to the mast-head, fitted with a seat and rest for a tclescope and a trap-door, to prevent cold air rising. The hold is divided into spaces called "pounds" by strong partitions, to prevent the cargo shifting with the lurch of the vessel. A tank fitted with a steam-pipe from the boilers, to convert ice into water, completes the list of exceptional fittings in these vessels. The water so made tastes like condensed water at first, but acquires the aëration more rapidly.

Twenty-three similarly fitted steamers went to the fishery this year. The crew, 273 in all, consisted of captain, masters of watches, engineers, firemen, cooks, stewards, and seamen. All share alike, except the captain, in the proceeds of the voyage; but the masters of watches, engineers, and firemen have their pay in addition. The captain has 6.t. currency for each young pelt brought in, and $1 s .3 d$. to Is. $6 c$. currency for each hundredweight of old seal blubber.

The men ship in one of three capacities, viz., "gunner," "gunner without gun," and "batsman." If there is much shooting, the gunners get each Ios. for the hire of their guns; those with no gun are supplied with them from the ship's stores.

The only necessaries for the men's outfit, besides woollen clothing, are a pair of sealskin boots with thick soles, a lacing at the top to tie them close round the calf of the leg and prevent water getting in, and large pyramidal nails, "frosters," or " sparrowbills," to avoid slipping on smooth ice. A sheath-knife, a small steel, and eye-preservers of glass with wire gauze surroundings, complete the list. 'The men are furnished from the ship's stores with bats, straight poles $4 \frac{1}{2} \mathrm{ft}$. long and $1 \frac{1}{2}$ in. diameter, and "starts," iron hooks and spikes, with a small piece bent at right angles to the butt to stick into the bat. A groove is cut in the latter, and the start is seized in the whole, constiluting a "gaff," and combining the uses of boat-hook and alpenstock. A hauling rope, about three fathoms of $I_{2}^{1}$ in. cordage, to lace up and drag on board the seals, is also supplied.

The men are divided into three watches under masters of watches, who choose their men in turn, one at a time, and each watch is again subdivided under quartermasters, who are responsible for their men on the ice and are furnished with two numbered flags bearing the ship's name. These numbers are entered against the names of those to whom they are given in a book kept for the purpose, enabling the captain to tell at a glance what men are away by the absence of flags. They are also divided into boats" crews, consisting of "bow" and "after" gunners and two oarsmen, chosen in a similar manner to the watches by the bow-gunners, who take charge of the punts, rough-built country boats, that are numbered to distinguish them. The Bear carried twenty-five of these punts.
The men in steamers divide amongst them one-third of the gross catch; the remainder goes to the owners for expenses of outfit and share of the profits. In sailing vessels the men share a half between them, but have to pay 1\%. to 2l. currency berth money for their chance. Nearly 8,500 men were engaged in the fishery during the spring of this year.

When young seals are met with, the men are sent on to the ice, equipped as described. If the seals are not numerous, the ship is kept as close as possible to them; each man secures as many as he can, and drags them to the ship, the first tow being the property of that man who sees the seals first. They are killed by blows on the nose with the gaff, and are then scalped, by drawing a line with the knife through the skin and blubber from chin to tail, and skinning until the ribs on the left side are reached. The knife is then stuck in the heart, to make a hole through which a finger can be thrust to grasp a rib, anc the carcase is held in that way till the pelt is removed. The scudders, or hinder flippers, are cat off, and when "panning," one of the foremost paws is taken out to make a hole through which to pass the slings for hoisting on board; but when towed to the ship both are left in to be eaten afterwards. "The fore-paws (or "flippers" in the vernacular) when roasted are esteemed great delicacies, and much attention is paid to the cook to obtain permis. sion to cook them.

As soon as a sufficient number are collected for a "tow" (six average-sized young ones being considered enough), the first is laced from the head through one or two holes cut close to the edges of the pelt, so that the hair is on the ice; the second skin is then laid half-way along the first, and the hauling-ropes passed for two turns through both, then for one turn through the second only. The third is then placed on the second, and so on to the last, when the end is made fast. The other end of the hauling-rope is passed through a hole cut in the nose of the first pelt, and a loop is made for one hand to grasp while the other grasps the end over one of the shoulders. The gaff is pushed through the tow-butt behind, and forms a tail to the whole. When the pelts are brought to the ship, they are hoisted thus on board, and each man unlaces his own to secure the hating-rope and gaff belonging to him.

When the vessel cannot get near the seals or they are extended over a large area, they are "panned" or collected in heaps, each marked with a flag by the different sub-divisions. When taken to the pan the pelts are unlaced and stowed flat, with the hair on the ice, to prevent the sun burning them. If night comes on before the pan is picked up by the ship, a lantern is sent and is watched by a man till the vessel arrives. With the prospect before them of a whole night to be so passed, the men take axes to make ice-houses, and light a fire of the carcases to keep themselves warm. Often, however, the only chance of the men being picked up is to remain by the pan until the ship arrives, without any material to shelter or keep themselves warm.

The pelts are kept on deck at least one night to cool, and are then stowed in the pounds as soon as time permits; otherwise they are a most unsafe deck cargo, threatening to lurch with each motion of the vessel. "Sish," or broken up ice, is sometimes placed between the layers of skins; they are counted when stowed, and the account is kept by the senior "master of watch."

The system of capture is the same with the old seals, but one is considered enough for a tow, and shooting is often resorted to when the ice is at all open, and becomes a necessity in the case of the male "Hood," who fights desperately.

When the vessels are fast in the ice and no seals are near, the gunners are sent away "swatching," or waiting an opportunity to shoot any that may show themselves in the lakes of water near. When sent away for long distances, the men carry a board to rest on, and build ice- 
houses to protect them from the wind; but at the best it is bitterly cold work. They also take a few biscuits with them, and eat, in addition, the hearts of the young seals, uncooked. The signals for recall are the ensign at the mast-head in clear, and the steam whistle in foggy weather.

The seals taken generally are of two kinds, "Harps," or Saddle-back, and "Hoods," or Bladder-nose Seal.

The "Harps" are distinguished by the sealers as "White Coats" when young, from their colour; "Dippers" after the white coat has fallen off and the spotted skin shows; "Bedlemers" till the saddle or harp is formed; and "Saddle Harps" when they arrive at maturity. "Jennies" or "Tuckers" are the females in the first year of whelping, and "Lords" or "Noggerheads" those deformed from the want of proper nourishment consequent on the mother being driven away or killed. Harps have black claws.

The "White Coat" remains perfectly passive to be killed, and the "Dipper" may be attracted by whistling or singing, and approached till within striking distance; but the mothers take to the water and desert their pups at the slightest alarm. The males are never with their families, but are always to be found on the south-west edge of the whelping ice. This generally consists of ice made on the coast of Labrador with small hummocks on it, that give shelter to the young from the north-easterly winds, the approach of which may be known by the incessant crying of the young Harps. The "harp" or saddle begins to form at the age of one year, is perceptible at the second, and perfect at the third. After that it is difficult to judge the age, but the teeth generally give evidence of extreme age.

The "Hood" is much the finer kind in size and appearance, and is so called from an air-bag covering the head of the full-grown male, that can be inflated at will, and is so when danger is apprehended. It resists completely the blows from a gaff, and the slugs used in sealing do not penetrate it except at close quarters. They can, however, bc killed by a blow under and along the line of the jaw, but considerable dexterity is required to effect this, and they can be shot dead by hitting them behind the air-bag or hood. They live in "families," male, female, and pup. Unlike the "Harps," the female rarely deserts her young, but makes a feeble and ineffectual defence in its behalf, and is killed by its side; and in most cases the male offers a desperate resistance, making it unsafe for one man to attack it. They have white claws, and the male attains a length of $7 \mathrm{ft}$., and has a beautiful dark spotted skin. The young are white with a black stripe down the back, and rarely cry, nor have either sex any sign of the hood. The ice on which they whelp is heavy Arctic ice, rafted into large hummocks, and is generally to the north-eastward of the "Harps." The young of this species come to maturity and take to the water earlier than the "White Coats."

The females of both species are ready for fishing as soon as the young are born, and beat inshore to the shoal fishing-grounds, returning with unerring certainty to the pan on which they had left their young, notwithstanding wheel or drift of ice in the interval. The inference on secing old seals is that the young are outside; they are never to be seen northward of their whelps. Both species have the power of protruding and withdrawing the teat, so that after the young have suckled, no danger may accrue from crawling over the ice.

When the vessels have secured a large cargo, or at the latest by April Io, they return to St. John's to prevent the loss of the blubber by running from excess of heat. On the south side of the harbour large vats have been constructed, and machines erected for preparing and refining the oil from the blubber. The pelts are taken from the hold and passed through the hands of "skinners," who separate blubber from the skin, take out the flippers, cut off the noses, \&c. The blubber is then weighed and the quantity recorded as the catch, less $I \frac{1}{2}$ lbs. for each pelt to balance the flesh left on in scalping. The skins are counted and a deduction of sixpence currency made from their value for every hole found in addition to those necessary for lacing, \&c. "Cats" are pelts that weigh less than $25 \mathrm{lbs}$, and are not included with the other seals, but have a specially low market value of their own, that helps to prevent the animals being taken while too young.

The blubber is thrown into a trough and conveyed thence into tearing machines, two cylinders with rough teeth that grind the blubber and tear the vesicles; thence to tanks, where it is converted by steam into oil and conveyed to other receptacles. A further process of bleaching takes place in reservoirs covered with glass roofs, and sometimes lined with tin, that in a few days makes the oil as clear as water. The refuse is subjected to great pressure to take off the last and worst kind of oil, and is then sold for manure. Seal blubber is valuable in the following order, viz. : that of (1) Young Harp ; (2) Young Hood ; (3) Bedlemers ; (4) Old Harps ; (5) Male or "Dog" Hood; (6) Female Hood. The blubber of the last is of much the least value as the small amount of oil contained tints with a yellow colour oil from the other species, and the vesicles are so tough as occasionally to break the teeth of the tearing machines. The skins are salted and exported to England, where they are converted into fine leather and used in the manufacture of ladies' boots.

If the vessels are cleared before April 15, they make a second voyage and hunt the Dippers and old Harps, prin. cipally the latter. The Hoods, both old and young, have by that time entirely disappeared. In rare successful cases a third trip is sometimes made, and the vessels do not return till the middle of May. The catch of 1874 has been very poor, from a great number of very young seals having been taken, but in former years as many as 33,000 have been brought in by a steamer from the first voyage.

The ice encountered in the course of the voyage is of various kinds. In mild winters large areas of "sish," or frozen snow and salt water, are met with. This is most difficult to walk on, and the men rarely escape a cluckins during a day's tramp. Harp ice is the next in point of thickness, and is generally rafted ice made on the Labrador shore, while the heaviest, or true Arctic ice, large hummocks and heavy pans, is the favourite place of resort for Hoods. Though all icebergs travel from the nortb, those predominating this year were large, low, and flat; one was seen from twenty to forty feet in height, that was quite two miles measured diagonally. It is dangerous to try to cross their track, because the ice is packed by the pressure of the berg, so that not even a powerful steamer can force her way through. Ice navigation is very uncertain from many causes, but principally from tides, currents, and "wheel" of the ice. When near the land the two former have to be specially guarded against, as the surrounding ice remains the same and gives no evidence of the change of position. In one case a drift of twenty-five miles was experienced in two days; ship, icebergs, and field ice remaining in exactly the same relative positions.

The "wheel" of the ice is caused by pressure of heavier" ice on one corner of the field, causing the latter to turn as on a pivot in the direction of the pressure. This is quite uncertain in direction and speed, and no experience can foresee either. Running ice is also a source of danger to vessels fast in it, as they are propelled with irresistible force against any obstacles to their progress-icebergs, rocks, \&c. In the spring of 1872 a steamer (Wolf) was crushed in an instant by that means, and the vessel went down before the men had time to secure their clothes. Often before a breeze of wind comes the ice rafts or squeezes, layer on layer, with a creaking sound. This also occur's in heavy squalls, and is a source of great danger to vessels fast in heayy ice. 
In foggy or stormy weather, the vessel is kept under command, if possible, to clear any icebergs seen, but if not able to move, should be placed broadside to the wind or before it ; the danger of being head to wind is, that if the ice anchors carry away and a crack forms under the stern, the force of concussion with the ice may damage the rudder fittings irreparably.

When crossing the water at night and approaching ice, the vessel is always stopped to take the shock gently, and because icebergs loom much like field ice. The whereabouts of water is inevitably shown by a dark horizon, and that of ice by the blink or "glinny."

There are no laws regulating the prosecution of the seal fishery except one passed in 1873 , forbidding the departure of sailing vessels before the 5 th, and steamers before the Ioth of March.

Little Placentia, Newfoundland, June 22

\section{THE INTERNATIONAL GEOGRAPHICAL CONGRESS}

THE Organising Committee of the Geographical Congress to be held in Paris in the spring of 1875 have josned a programme of subjects to be discussed during the meeting. The "Commissaire Général" of the Congress is M. le Baron Reille, to whom, at Io, Boulevard Latour-Maubourg, all communications ought to be addressed. The Congress will last eight days, the first of which will be devoted to a general meeting for the purpose of inaugurating the work of the Congress. The members will be divided into sections, each of which will meet separately on the following forenoons to discuss the subjects connected with the section; the afternoons will be devoted to general séances. Duxing the meeting of the Congress there will be an exhibition of objects relating to the study of geography, and on the last day prizes will be awarded to exhibitors. The transactions of the Congress will be ultimately published. The conditions of subscription are much the same as those of the French Association for the Advancement of Science.

The sectional sub-committees have provisionally prepared a series of questions for discussion under each section; proposed additions to or modifications of these should be addressed to $M$. le Baron Reille as above. The sections are as follows:-

I. Mathematical Section, including Mathematical Geo graphy, Geodesy, and Topography. The following are some of the questions to be discussed in this section:Substitution of the centesimal division of the quadrant for the division called sexagesimal; consequences relative to the division of time in astronomy.-Choice of a zero for a general level.--Measure of the differences of longitude; utilisation of telegraphic lines for the purpose of determining longitudes; advantages to geography by the electric telegraph.-Employment of chronometers. Measure of an arc of the meridian in the southern hemisphere, and particularly in the Argentine Republic.-The most simple instruments and the quickest methods for determining magnetic declination.

II. Hydrographical Section, including Hydrography and Maritime Geography.-Among the questions to be discussed in this section are the following :-Choice of a simple and uniform method for reckoning the points of the compass. - Researches concerning the depth to which the agitation of the surface of the sea penetrates.--Study of marine currents; question of the currents in straits.Determination of the temperature of the sea at different depths; instruments used; selection of the special points where these observations ought to be made.-Causes of the temperature of the Gulf Stream.-Programme of international instructions relative to observations which could usefully be made at once.

III. Physical Section, including Physical Geography General Meteorology, General Geology, Botanical and
Zoological Geography, General Anthropology. Among the subjects proposed for discussion in this section are :New and well-established facts relative to the mobility of the crust of the earth during historical times.- Various theories as to the origin of mountains.--Lithology of the bed of the ocean, - Actual results of recent researches on the influences exercised by astronomical phenomena, such as solar spots, meteoric showers, \&c.-To investigate new facts relative to the circulation of the atmosphere and the ocean, the movements of aërial and maritime currents, and their influence upon climates.-To discover the origin and general progress of great atmospheric whirlwinds or cyclones, as well as their periods; to determine their duration, their force, and the extent of the countries exposed to their effects.-Means to be adopted in order to extend more widely the establishment and the discussion of simultaneous meteorological observations, recommended by the International Congress at Vienna.Geographical distribution of animal and vegetable species during tertiary times; consequences which fiow therefrom relative to the climatology of the globe during that period; geographical relation between the quaternary and the existing fauna and flora ; extinctions and migrations ; distribution of land and water during that period.-Species, genera, and families of plants which are characteristic of the great natural regions.-Also many questions relative to the geology, zoology, botany, anthropology, \&c., of the various great divisions of the globe-Europe, Asia, America, Oceania.

IV. Historical Section, including Historical Geography and the History of Geography, Ethnography, and Philology.--This section includes questions as to the condition of man both in prehistoric and historical times, comprehending the discussion of many particular points of history and ethnography.

V. Econonical Section.-This section is concerned with subjects connected wirh Econonical, Commercial, and Statistical Geography.

VI. The Didactic Section will discuss questions connected with Geographical Education and the diffusion of Geographical Knowledge.

VII. Section of Voyages, including explorations and voyages, scientific, commercial, and picturesque. In this section such points as the following are proposed for dis cussion :- How could a permanent bureau be constituted to indicate to travellers, by land and sea, the desiderato of geographical science?-Ouestions as to the undiscovered portion of Africa, as to the equipment of voyagers and travellers, instruments for various purposes, the bearing of explorers towards natives, narratives of travel, \&c., \&c.

There are proposed for discussion in the seven sec. tions in all 123 questions, of which the abovs are a sample; and it will be seen, we think, that if the right men are induced to attend the Congress, and if the discussions are conducted in a truly scientific and candid spirit, great good must be the result to the many branches of science which are more or less connected with the subject of geography.

\section{THE LAST NEW COMET}

M R. J. R. HIND, F.R.S., writes as follows to the I Tines from Mr. Bishop's Observatory, Twickenham, August I :- "From three consecutive nights' observations of the new comet of Marseilles, received from M. Stephan, I have calculated a first approximation to the orbit. It appears the comet will not reach its perihelion till about the 25 th inst., but is already slowly receding from the earth, being distant, from us at the time of discovery about $55,000,000$ miles. Though it may continue visible in good telescopes for several weeks, it is not likely to become an object of any general interest, like the comet which has just left this hemisphere. The elements bear no resemblance to those of any comet previously computed." 